\title{
Milling Examination on CFRP Composites for Automobile Structures
}

\author{
K. M. John, S. Thirumalai Kumaran
}

\begin{abstract}
The CFRP is widely used in automobiles to reduce vehicle weight and give higher fuel efficiency due to greater strength to weight ratio. It should be needed to machine with accurate structure and integrity. The post curing process is necessary after machining the CFRP composite material to remove burr and delamination. The dual helix mill tool is used to perform slotting to eliminate burr formation and delamination. From the study there is no delamination is occurred when CFRP is machined at the cutting speed of $2500 \mathrm{rpm}$, feed rate of 600 $\mathrm{mm} / \mathrm{min}$ and $1 \mathrm{~mm}$ depth of cut and also burr formation is highly reduced at this condition.
\end{abstract}

Keywords: CFRP, milling, structure.

\section{INTRODUCTION}

$\mathrm{T}_{\mathrm{h}}$ he rapid use of CFRP in automobile is increasing nowadays because of superior strength to weight ratio. To make use of CFRP composites in automobiles, it is mandatory to machine composites with preferred structures, accuracy, and integrity is too tough. It is difficult to machine a composite laminates without any surface damage such as burr formation, delamination and poor surface roughness because of these high strength carbon fiber and adhesive plastics of the composite structures. There is lot of research is going on to reduce burr formation and delamination.

Masilamani et al. [1] reviewed on the usage of carbon fiber reinforced polymers in automobiles and concluded that $60 \%$ of weight is reduced when steel is replaced with CFRP and $40 \%$ of weight is reduced when aluminum is replaced as CFRP. Tie Wang and Yon gang Li [2] is analyzed the impact behavior of various thickness of car bumper. By changing the thickness weight is decreased and impact performance is better. Park et al. [3] evaluated the crash worthiness of CFRP ladder in the body-on-frame vehicle, it can give corresponding structural performance to the base line vehicle and it can give corresponding structural performance to the baseline vehicle in frontal impact configuration. Anwar et al [4] make better the mechanical properties of carbon fiber reinforced plastics to improve the crash worthiness probability by simulation impact testing. From the outcome the CFRP can withstand higher external load.

Azzam Ahmed and Li Wei [5] performed FE model of pedestrian head impact on CFRP material of automotive hood. From the collision test due to the reduction of HIC

Revised Manuscript Received on December 05, 2019.

* Correspondence Author

K. M. John, Department of Automobile Engineering, Kalasalingam Academy of Research and Education, Krishnankoil-626126, India. Email: john.aeronautics@gmail.com

S. Thirumalai Kumaran*, Faculty of Mechanical Engineering, Kalasalingam Academy of Research and Education, Krishnankoil-626126, India. Email: thirumalaikumaran@yahoo.com value and the higher deformation because of higher crash worthiness the steer hood can be replaced by CFRP. Gunyaev et al. [6] studied about the design of connecting rod using CFRP to reduce in weight and noise and also increasing automobile speeds. From the study it can be concluded that CFRP composites satisfies all the requirements and also it can be used in engines by replacing CFRP for steel.

Khairusshima et al. [7] performed milling on CFRP to reduce tool wear surface roughness using chilled air. From the result, concluded that tool wear is better at minimum feed rates and maximum cutting speeds. The surface roughness is reduced at higher cutting speeds. Avilla et al. [8] reviewed about the Finite Element (FE) modelling of burr formation in drilling of stacked material. From the result, by the use of consistent geometric software the burr formation is reduced.

Hintze et al. [9] have done an experimental study about the formation and development of delamination during machining of CFRP. The delamination is occurred according to the condition of tool and fiber orientation.

He et al. [10] conducted slot milling in CFRP with different cutting orientations and machining conditions to reduce cutting force. From the result of four fiber cutting angles the largest force exhibited on $0^{\circ} / 180^{\circ}$ and smaller one in $45^{\circ}$. The largest tangential force was appeared on $135^{\circ}$ and smaller one in $45^{\circ}$.

Karpat et al. [11] used double helix tools for machining. From the results, the helix tool is extended to $2 \mathrm{~mm}$ which is beyond the bottom of the composite laminate. After the 17 passes of the mill tool, the diamond coat is fractured due to milling force doubles (one pass corresponding to $900 \mathrm{~mm}$ ). Surface roughness increased from $2 \mu \mathrm{m}$ to $12 \mu \mathrm{m}$ between first and 17th pass. Number of tooth can be increased to achieve constant chip thickness. The diamond coat is fractured because of milling force.

Davin and Pedro Resis [12] approached to select machining parameters for damage-free drilling in CFRP composite material. From the result the delamination is higher when cutting parameter and feed is high.

Kanematsu et al. [13] have done experimental and investigation in fully clamped condition and vibration are obtained by holographic technique. From this study, the anisotropy faces of CFRP sandwich plate provided the satisfaction of boundary condition and this method is applicable for the anisotropy faces.

Hosokawa et al. [14] performed milling in CFRP composites using high helix end mill to increase surface integrity and to reduce tool wear. The smooth surface is occurred when high helix angle is used. There is no delamination is formed at exit layer when helix end mill is used. The high helix end mill 
can be used for end milling performance to achieve higher surface integrity and delamination free machining. Galvez et al. [15] studied about the behaviors of adhesive to connect a new concept made of carbon fiber composite to steel bus structures.

\section{EXPERIMENTAL PROCEDURE}

This study has been performed on M/s Lakhsmi Machine works Ltd make LMV JV 55 Vertical milling machine. Three stages of cutting speed (2000, 2500 and $3000 \mathrm{rpm})$, feed (400, 500 and $600 \mathrm{~mm} / \mathrm{min})$ and depth of cut $(0.5,0.75$ and $1 \mathrm{~mm})$ are determined. The constant length of cut is $25 \mathrm{~mm}$. The solid carbide, diamond coated, dual helix tool shown in Figure 1 has been used for machining. The tool has geometric parameters of $6 \mathrm{~mm}$ of diameter, $40^{\circ}$ of helix angle and 6 flute and it is presented in Fig. 1. The $90 \times 90 \times 5 \mathrm{~mm}$ unidirectional CFRP plates are used for slot milling study.

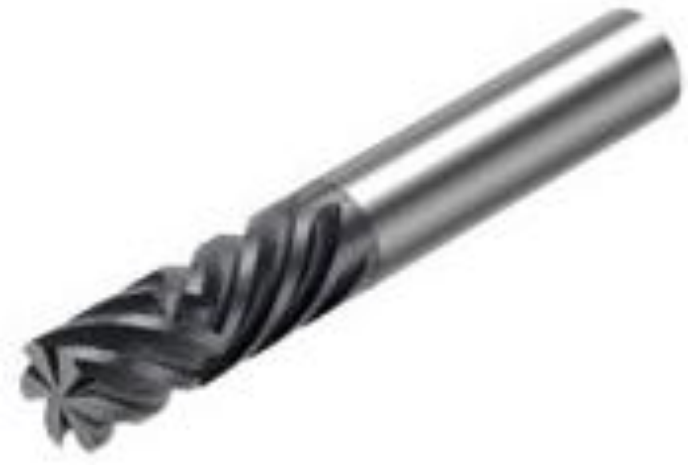

Fig. 1.Dual Helix Tool.

\section{RESULTS AND DISCUSSION}

The area of Burr and delamination are calculated from the slotted area. From the $31 \mathrm{~mm}$ of traverse length the slot is split up in to three parts for both delamination and burr calculation. The calculation of burr and delamination is done in Optimal Microscope.

Formulas used for the calculation of the slot:

Area of the Semi Circle $=\pi \mathrm{r} 2=28.274 \mathrm{~mm}$

Area of the Rectangle $=1 \times \mathrm{b}=150 \mathrm{~mm}$

Total area of the slot $=178.274 \mathrm{~mm}$

By adding the total area of burr and subtract with the area of slot, the final answer should be a burr area. It is repeated for all the cutting conditions. For the delamination area calculation the maximum length from the slot is taken and the area. It is repeated for all the machining conditions.

\section{A. Burr Formation}

The Figure 2 shows the graph of 0.5 depth of cut. The burr formation is higher at the feed of $600 \mathrm{~mm} / \mathrm{min}$ and the cutting speed of 3000rpm. The less amount burr is occurred at the feed of $400 \mathrm{~mm}$ and the cutting speed of 3000rpm.

Figure 3 shows the graph of 0.75 depth of cut. The higher amount of burr occurred in the condition of $2000 \mathrm{rpm}$ of spindle speed and $400 \mathrm{~mm} / \mathrm{min}$ of feed. The burr formation is low at $600 \mathrm{~mm} / \mathrm{min}$ of feed and $2000 \mathrm{rpm}$ of cutting speed. Figure 4 shows the graph of $1 \mathrm{~mm}$ depth of cut. The higher amount of burr is occurred at the condition of $600 \mathrm{~mm} / \mathrm{min}$ of feed and at $3000 \mathrm{rpm}$. The lower amount burr is occurred at $2500 \mathrm{rpm}$ of cutting speed and $600 \mathrm{~mm} / \mathrm{min}$ of feed.

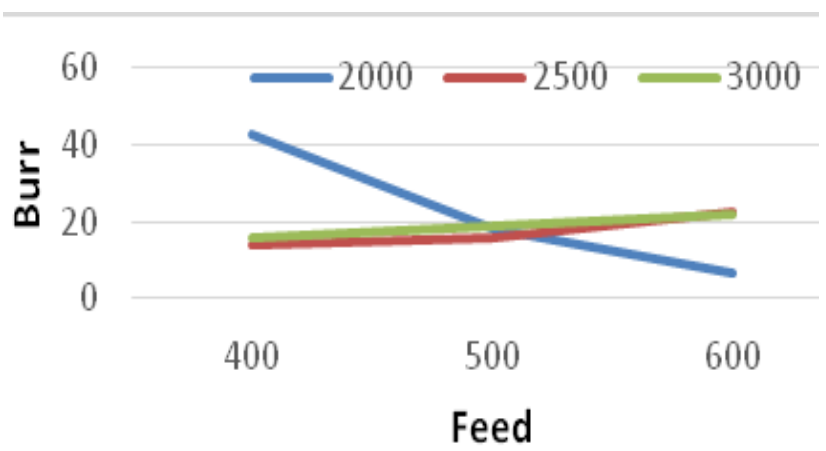

Fig. 2. Burr formation (0.5 $\mathrm{mm}$ depth)

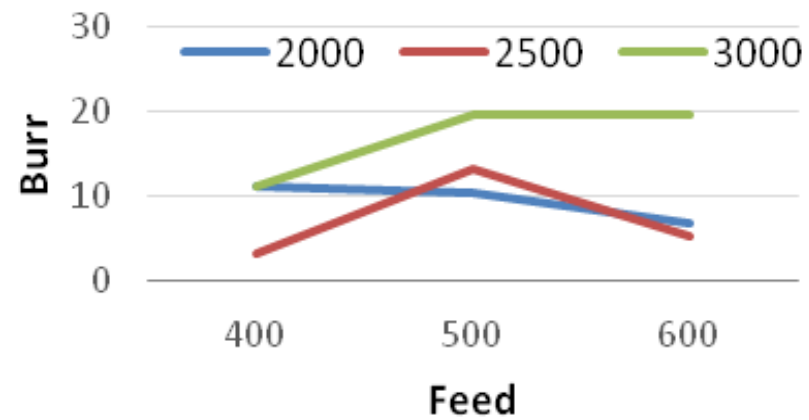

Fig. 3. Burr formation (0.75 $\mathrm{mm}$ depth)

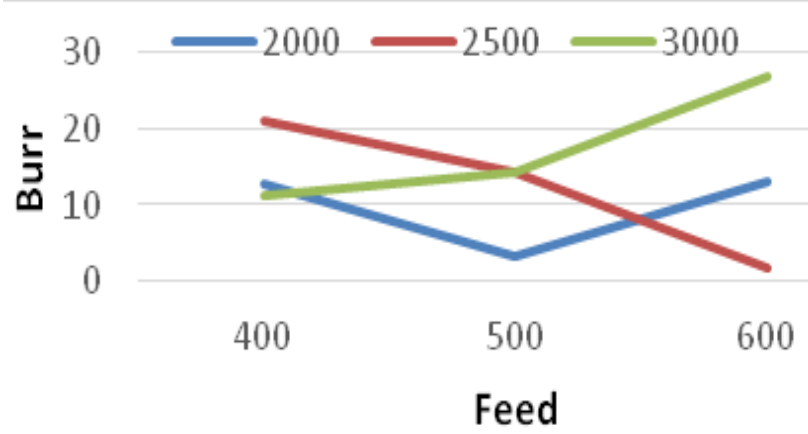

Fig. 4. Burr formation (1 mm depth)

\section{B. Delamination}

Figure 5 shows the graph of 0.5 depth of cut. There is no delamination occurred at $2500 \mathrm{rpm}$ of cutting speed and $600 \mathrm{~mm} / \mathrm{min}$ of feed. The higher delamination is occurred at $2000 \mathrm{rpm}$ of cutting speed and $600 \mathrm{~mm} / \mathrm{min}$ of feed.

Figure 6 shows the graph of $0.75 \mathrm{~mm}$ of feed. The higher amounts of delamination occurred at $2500 \mathrm{rpm}$ of cutting speed and feed rate of $400 \mathrm{~mm} / \mathrm{min}$, and lower at spindle speed of $3000 \mathrm{rpm}$ and $400 \mathrm{~mm} / \mathrm{min}$ of feed. Figure 7 shows the graph of $1 \mathrm{~mm}$ depth of cut. There is no delamination occurred at the cutting condition of $500 \mathrm{~mm} / \mathrm{min}$ of feed and speed of $2000 \mathrm{rpm}$ and also in $2000 \mathrm{rpm}$ of cutting speed and $600 \mathrm{~mm} / \mathrm{min}$ of feed. The delamination is occurred according to the condition of the tool [7].

From the three graphs the delamination is occurred when increasing the feed rate and depth of cut at $2500 \mathrm{rpm}$ of cutting speed. By comparing the graphs of burr formation and delamination the suitable cutting condition for CFRP composite is at $600 \mathrm{~mm} / \mathrm{min}$ of feed and $1 \mathrm{~mm}$ of depth of cut at $2500 \mathrm{rpm}$ of cutting speed.

Published By:

Blue Eyes Intelligence Engineering \& Sciences Publication

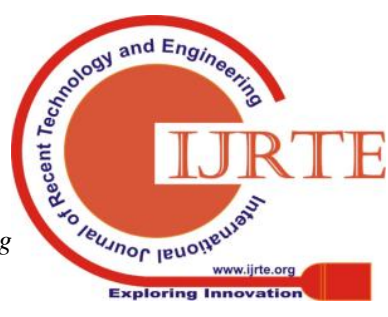




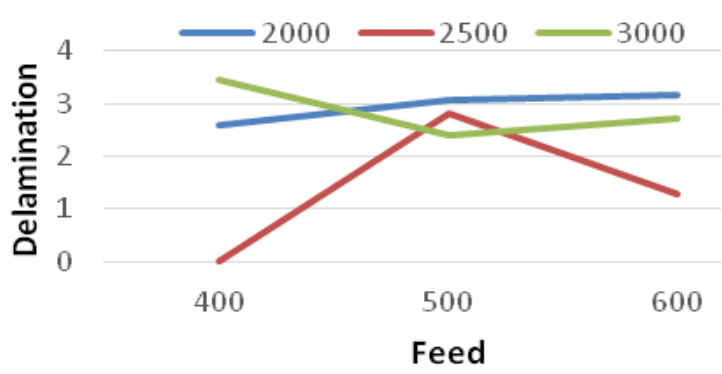

Fig. 5. Delamination (0.5 $\mathrm{mm}$ depth).

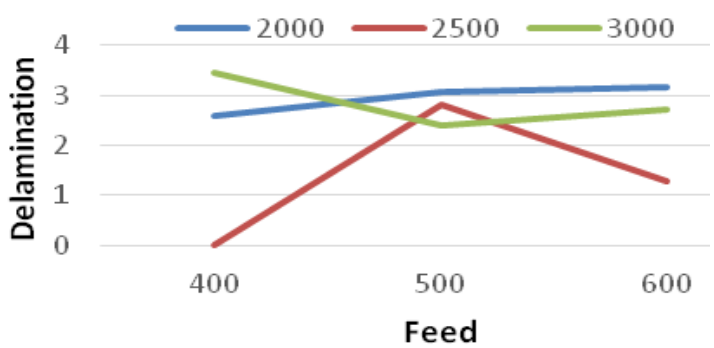

Fig. 6. Delamination (0.75 $\mathrm{mm}$ depth).

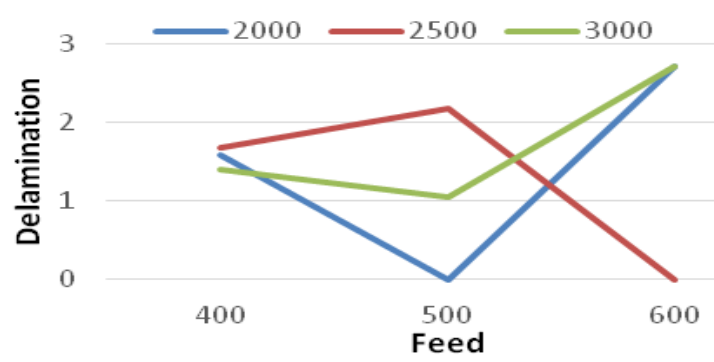

Fig. 7. Delamination (1 $\mathrm{mm}$ depth).

\section{CONCLUSION}

The delamination and burr formation is major problem when machining CFRP and avoiding this can be reduction of time and cost savings. This project describes the occurrence of burr formation and delamination when machining CFRP. From the result it can be concluded that by increasing the depth of cut and feed rate and at moderate spindle speed, the delamination and burr formation is reduced. From the findings the delamination and burr is highly avoided.

\section{REFERENCES}

1. R.Masilamani, N.V. Dhandapani, K. Vignesh Kumar and K. Tamil Mani, "A review on usage of carbon fiber reinforced plastics in automobiles," International Journal of Pure and Applied Mathematics, vol. 117, 2017, pp. 537-544.

2. Tie Wang and Yonggang $\mathrm{Li}$, "Design and analysis of automotive carbon fiber composite bumper beam based on finite element analysis," Advances in Mechanical Engineering, vol. 7, 2015, pp. 1-12.

3. Chung-Kyu Park, Cing-Dao (Steve) Kan and William Thomas Hollowell, "Evaluation of crashworthiness of a carbon-fibre-reinforced polymer (CFRP) ladder frame in a body-on-frame vehicle," International Journal of Crashworthiness, vol. 19, 2013, pp. 27-41.

4. Miftahul Anwar, C.Sukmaji Indro, R.Wijang Wisnu and Kuncoro Diharjo, "Application of carbon fiber-based composite for electric vehicle," Advanced Materials Research, vol. 896, 2014, pp. 574-577.

5. Azzam Ahmed and Li Wei, "Introducing CFRP as an alternative material for engine hood to achieve better pedestrian safety using finite element modeling," Thin-Walled Structures, vol. 99, 2016, pp. 97-108.

6. G. M. Gunyaev, S. M. Borovskaya and V. I. Panin, "Using CFRP for the design of a connecting rod for automobile applications," Proceedings of the Institution of Mechanical Engineers, Part D: Journal of Automobile Engineering, vol. 208, 1994, pp. 33-36.
7. M. K. Nor Khairusshima, C. H. Che Hassan, A. G. Jaharah and A. K. M. Nurul Amin, "Tool wear and surface roughness on milling carbon fiber reinforced plastic using chilled air," Journal of Asian Scientific Research, vol. 2, 2012, pp. 593-598

8. Miguel Ávila, Joel Gardner, Corinne Reich-Weiser, Shantanu Tripathi, Athulan Vijayaraghavan and David Dornfeld, "Consortium on Deburring and Edge Finishing," UC Berkeley, 2006, 05AMT17.

9. Wolfgang Hintze, Dirk Hartmann and Christoph Schütte, "Occurrence and propagation of delamination during the machining of carbon fibre reinforced plastics (CFRPs) - An experimental study," Composites Science and Technology, vol. 71, 2011, pp. 1719-1726.

10. Yanli He, Huanan Qing, Shengguang Zhang, Dazhen Wang and Shengwei Zhu, "The cutting force and defect analysis in milling of carbon fiber-reinforced polymer (CFRP) composite," International Journal of Advanced Manufacturing Technology, vol. 93, 2017, pp. 1829-1842.

11. Yigit Karpat and Naki Polat, "Mechanistic force modeling for milling of carbon fiber reinforced polymers with double helix tools," CIRP Annals - Manufacturing Technology, vol. 62, 2013, pp. 95-98.

12. J.P. Davim and Pedro Reis, "Study of delamination in drilling carbon fiber reinforced plastics (CFRP) using design experiments," Composite Structures, vol. 59, 2003, pp. 481-487.

13. Henrique Hiroshi Kanematsu, Yoichi Hirano and Hisashi Iyama, "Bending and vibration of CFRP-faced rectangular sandwich plates," Composite Structures, vol. 10, 1988, pp. 145-163.

14. Akira Hosokawa, Naoya Hirose, Takashi Ueda and Tatsuaki Furumoto, "High-quality machining of CFRP with high helix end mill," CIRP Annals - Manufacturing Technology, vol. 63, 2014, pp. 89-92.

15. Pedro Galvez, Alejandro Quesada, Miguel Angel Martinez, Juana Abenojar, Maria Jesus L. Boada and Vicente Diaz, "Study of the behavior of adhesive joints of steel with CFRP for its application in bus structure," Composites Part B, vol. 129, 2017, pp. 41-46.

\section{AUTHORS PROFILE}

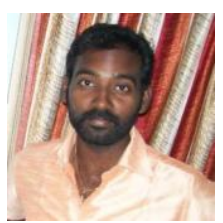

K. M. John is a Research Scholar in Department of Automobile Engineering at Kalasalingam Academy of Research and Education, Krishnankoil. He holds University Second Rank in Master of Engineering (CAD/CAM) from VV College of Engineering, Thisyanvillai and Bachelor of Engineering (Aeronautical) from Gojan School of Business and Technology, Chennai.

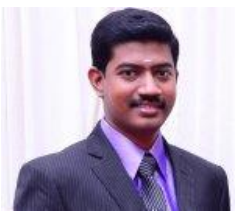

S. Thirumalai Kumaran completed his $\mathrm{Ph} . \mathrm{D}$. degree in Mechanical Engineering from Kalasalingam Academy of Research and Education (KARE), India, in 2015. After completing Ph.D., he worked as an Assistant Professor at School of Mechanical Engineering, Yeungnam University, South Korea for a period of one year. He is currently an Associate Professor at School of Automotive and Mechanical Engineering, KARE. 